GLOBAL JOURNAL OF EDUCATIONAL RESEARCH VOL 13, 2014: 1-7 COPYRIGHTৎ BACHUDO SCIENCE CO. LTD PRINTED IN NIGERIA. ISSN 1596-6224

\title{
EFFECT OF DIFFERENTIATED INSTRUCTIONAL STRATEGIES ON STUDENTS' RETENTION IN GEOMETRY IN FCT SENIOR SECONDARY SCHOOLS, ABUJA, NIGERIA
}

\section{R. A. OGUNKUNLE AND ONWUNEDO AZUKA HENRIETTA}

(Received 17, January 2014; Revision Accepted 17, February 2014)

\begin{abstract}
The effect of differentiated instructional strategies on students' retention in geometry in senior secondary schools was examined. The study employed experimental research design of pretest, posttest control group. The area of this study is Abuja Municipal Area Council, the Federal Capital Territory. The target population was the entire mathematics student in senior secondary class 2 (SS2) in the area. The simple random sampling technique was adopted and used to select two senior schools and 100 subjects for the study. Researcher-designed Geometry Achievement Test (GAT) containing 25 multiple choice items with reliability coefficient of 0.90 was used to measure students' academic achievement before and after treatment. The researcher taught the experimental and control groups for six weeks. At the beginning and end of the six weeks GAT was administered as a pre-test and post-test to the students in the two groups. The result shows among others that differentiated instructional strategies was more effective in promoting meaningful learning and enhancing mathematics students' achievement than the conventional method $\left(Z_{98}=11.320, p<.05\right)$. The result of the post-post-test administered to the experimental and control group students' four weeks after the first post-test also show that retention ability was significantly higher in the experimental group students than in the control group student $\left(z_{98}=13.876, p<.05\right)$. Conclusion from these findings led to the recommendation that Mathematics teachers and educators should adopt the Differentiated instructional strategies as an Innovative, efficient and effective strategy in teaching geometry concepts in Mathematics.
\end{abstract}

KEYWORDS: Differentiated instruction, Lecture , Cognitive Achievement ,Retention ability, Geometry.

\section{INTRODUCTION}

Experience for the past years as Mathematics educator has shown that not all students are alike. No two students enter a classroom with identical abilities, experiences and needs. Learning style, language proficiency, background knowledge, readiness to learn, and other factors vary widely within a single class group. Regardless of their individual differences, however, students are expected to master the same concepts, principles, and skills. Helping all students succeed in their learning is an enormous challenge that requires innovative thinking. Based on this knowledge, differentiated instruction applies an approach to teaching and learning that gives students multiple options for taking in information and making sense of ideas. Differentiated instruction is a teaching theory based on the premise that instructional approaches should vary and be adapted in relation to individual and diverse students in classrooms (Tomlinson, 2001). The model of differentiated instruction requires teachers to be flexible in their approach to teaching and instruction. It allows teachers to face this challenge by taking diverse student factors into account when planning and delivering instruction. The idea of differentiating Mathematics instruction to accommodate the different ways

R. A. Ogunkunle, Department of Curriculum Studies and Educational Technology Faculty of Education University of Port-Harcourt, Port-Harcourt, Nigeria.

Onwunedo Azuka Henrietta, Government Secondary School Nyanya, Abuja, Nigeria. 
that students learn involves a hefty dose of common sense, as well as sturdy support in the theory and research of education (Allan \& Tomlinson 2000). It is an approach to teaching that advocates active planning for student differences in classrooms. Theroux (2004) addressed four ways to differentiate instruction:

- content (requires pre-testing to determine the depth and complexity of the knowledge base that learners will explore)

- process (leads to a variety of activities and strategies to help students gain knowledge)

- product (complexity varies in ways for assessing learning)

- Manipulating the environment or accommodating learning styles

\section{Content}

Several elements and materials are used to support instructional content. These include acts, concepts, generalizations or principles, attitudes, and skills. The variation seen in a differentiated classroom is most frequently in the manner in which students gain access to important learning.

Align tasks and objectives to learning goals. The alignment of tasks with instructional goals and objectives as essential in learning, planning and instruction, Goals are most frequently assessed by many state-level, highstakes tests and frequently administered standardized measures. Objectives are frequently written in incremental steps resulting in a continuum of skills-building tasks. An objectives-driven menu makes it easier to find the next instructional step for learners entering at varying levels.

Instruction is concept-focused and principle-driven. The instructional concepts should be broad-based, not focused on minute details or unlimited facts. Teachers must focus on the concepts, principles and skills that students should learn. The content of instruction should address the same concepts with all students, but the degree of complexity should be adjusted to suit diverse learners.

\section{Process}

Flexible grouping is consistently used. Strategies for flexible grouping are essential. Learners are expected to interact and work together as they develop knowledge of new content. Teachers may conduct whole-class introductory discussions of content big ideas followed by small group or paired work. Student groups may be coached from within or by the teacher to complete assigned tasks. Grouping of students is not fixed. As one of the foundations of differentiated instruction, grouping and regrouping must be a dynamic process, changing with the content, project, and on-going evaluations.

Classroom management benefits students and teachers. To effectively operate a classroom using differentiated instruction, teachers must carefully select organization and instructional delivery strategies.

\section{Products}

Initial and on-going assessment of student readiness and growth are essential. Meaningful pre-assessment naturally leads to functional and successful differentiation. Incorporating pre and on-going assessment informs teachers so that they can better provide a menu of approaches, choices, and scaffolds for the varying needs, interests and abilities that exist in classrooms of diverse students. Assessments may be formal or informal, including interviews, surveys, performance assessments, and more formal evaluation procedures.

Students are active and responsible explorers. Teachers' respect that each task put before the learner will be interesting, engaging, and accessible to essential understanding and skills. Each child should feel challenged most of the time.

Vary expectations and requirements for student responses. Items to which students respond may be differentiated so that different students can demonstrate or express their knowledge and understanding in different ways. A well-designed student product allows varied means of expression and alternative procedures and offers varying degrees of difficulty, types of evaluation, and scoring.

\section{Statement of the problem}

Today's classrooms are becoming more academically diverse. Many, if not most, classrooms contain students representing both gender and multiple cultures, frequently include students who do not speak English as their first language, and generally contain students with a 
range of exceptionalities and markedly different experiential backgrounds. These students certainly work at differing readiness levels, have varying interests, and learn in a variety of ways. Mathematics teachers will find it difficult to consistently find single tasks that are moderately challenging for all learners in a class that includes a range of readiness and experiential levels. The problem of this study therefore was to investigate the effect of differentiated instructional strategies on Mathematics achievement and retention of senior secondary students in Abuja Municipal Area Council of the Federal Capital Territory, Nigeria.

\section{Purpose of the study}

Specifically, this study was designed to ascertain if

1. there is any difference in the cognitive achievement of senior secondary students taught geometry with differentiated instructional strategies and those taught using conventional method?

2. any difference exists in the retention of concept between senior secondary students taught geometry using differentiated instructional strategies and those taught using conventional method?

\section{Research Questions}

To enhance the successful conduct of this study, the following research questions were raised in the study:

1. What is the difference between the cognitive achievements of senior secondary students taught Geometry with differentiated instructional strategies and those taught using conventional method?

2. What difference exists in the retention of concept between senior secondary students taught Geometry using differentiated instructional strategies and conventional method?

\section{Hypotheses}

The following hypotheses were formulated in this study:

$\mathrm{H}_{01}$ There is no significant difference between the cognitive achievement of senior secondary students taught geometry using differentiated instructional strategies and those taught using conventional method?
$\mathrm{H}_{02}$ Senior secondary students taught geometry using differentiated instructional strategies do not perform significantly better in their retention of concepts than those taught using conventional method.

\section{Methodology}

The study utilized pretest, posttest control group experimental research design. The population is the entire senior secondary two mathematics students in FCT Abuja. The sample consisted of 100 Senior Secondary two (SS2) students randomly selected from two out of 17 senior secondary schools in Abuja Municipal area Council, FCT, Nigeria. Simple random sampling technique was used to select the two schools and the 100 students using the hat-draw method. Finally, the same technique was used in assigning a particular class to either experimental or control group. The experimental group consisted of 50 students made up of 25 female and 25 males while the control group consisted of 50 students made up of 25 female and 25 males. The instrument used for data collection was Geometry Achievement Test (GAT) consisting of 25 four-option, multiple choice items designed by the researchers and validated by two resource persons in Mathematics education. The items were trail tested on twenty students in a school different from those used for the study. The reliability index of this instrument is 0.90 using test re-test method. Permission was sought from the principals of the selected schools to allow their schools to be used for the study. The researcher effectively taught the experimental group using differentiated instructional strategies (pre-assessment, flexible grouping, tiered instruction and assessment) and also taught the other students (Control group) with conventional strategy on concepts in geometry during school hours (precisely during the periods of mentoring, clubs and societies). This was done for six weeks. At the beginning and end of the six weeks GAT was administered as a pre-test and posttest to the students in the two groups. After four weeks of post-test, the GAT was reshuffled and administered as retention test. The researchers computed means and standard deviations to answer the research questions while Z-test was used to test the hypotheses at 0.05 level of significance. Z-test was used because with randomization of subjects all known and unknown sources of extraneous variables are 
prevented from systematically biasing results of an investigation (kpolovie, 2010).

Results

Research question 1: What is the difference between the cognitive achievements of senior secondary students taught geometry with differentiated instructional strategies and those taught using conventional method? The result is presented in table 1

Table 1: Mean achievement scores and standard deviations of subjects in the experimental and control groups in GAT

\begin{tabular}{|c|l|l|l|l|l|}
\hline Group & N & $\begin{array}{l}\text { Pre-test } \\
\text { Mean }\end{array}$ & SD & $\begin{array}{l}\text { Post-test } \\
\text { Mean }\end{array}$ & SD \\
\hline DIS & 50 & 27.42 & 6.56 & 59.36 & 11.55 \\
\hline CVM & 50 & 25.96 & 5.72 & 38.68 & 5.79 \\
\hline
\end{tabular}

DIS: Differentiated Instructional Strategies, CVM: Conventional Method.

Table 1 shows that mean achievement scores of students taught with DIS was 59.36, standard deviation was 11.55 while that of the students taught with CVM was 38.68 with standard deviation of 5.79 . This implies that DIS was more beneficial in improving the students' cognitive achievement than the conventional method (CVM). Hypothesis 1 was tested to confirm this answer.

$\mathrm{H}_{01}$ There is no significant difference between the cognitive achievement of senior secondary students taught geometry using differentiated instructional strategies and those taught using conventional method? The analyzed data for testing hypothesis 1 is found in table 2 .

Table 2: Z-test on difference between the cognitive achievement of senior secondary students taught geometry using differentiated instructional strategies and those taught using conventional method.

\begin{tabular}{|c|c|c|c|c|c|c|c|}
\hline Method & $\mathbf{N}$ & $\bar{X}$ & SD & df & z-cal. & z-crit. & Result \\
\hline DIS & 50 & 59.36 & 11.55 & \multirow[t]{2}{*}{98} & \multirow{2}{*}{$\begin{array}{c}11.320 \\
*\end{array}$} & \multirow[t]{2}{*}{1.960} & \multirow[t]{2}{*}{ Significan } \\
\hline CVM & 50 & 38.68 & 5.79 & & & & \\
\hline
\end{tabular}

Result in table 2 indicates that the noted difference between the mean achievement scores of those taught with DIS and those taught with the CVM is significant at .05 alpha levels. The null hypothesis was rejected. This implies that DIS is more efficacious than the conventional method.
Research question 2: What difference exists in the retention of concept between senior secondary students taught geometry using differentiated instructional strategies and conventional method? Answer to research question 2 is found in table 3. 
Table 3: Mean retention scores and standard deviation in GAT of subjects in the experimental and control groups

\begin{tabular}{|l|l|l|l|l|l|}
\hline Group & N & Posttest mean & SD & Retention mean & SD \\
\hline DIS & & & & 60.42 & \\
& 50 & 59.36 & 11.55 & & 11.46 \\
\hline CVM & & & & 34.08 & 6.72 \\
& & & 5.79 & & \\
\hline
\end{tabular}

Table 3 shows that the mean retention scores of students taught with DIS was 60.42 , standard deviation was 11.46 , while that of those students taught with CVM was 34.98with standard deviation of 6.72 . This implies that DIS is more effective than CVM in teaching
Geometry. Hypothesis 2 was further tested to confirm this result.

$\mathbf{H}_{02}$ Senior secondary students taught geometry using differentiated instructional strategies do not perform significantly better in their retention of concepts than those taught using conventional method.

Table 4: Z-test on difference between the retention of concept of senior secondary students taught geometry using differentiated instructional strategies and those taught using conventional method.

\begin{tabular}{|l|l|l|l|l|l|l|l|}
\hline Method & N & - & SD & df & z-cal. & z-crit. & Result \\
\hline DIS & 50 & 60.42 & 11.46 & 98 & $13.876^{*}$ & 1.960 & Significant \\
\hline CVM & 50 & 34.98 & 6.72 & & & & \\
\hline \multicolumn{7}{|c|}{$\boldsymbol{p}<.05$}
\end{tabular}

Result in table 4 shows that the noted difference between the mean retention scores of those taught with DIS and those taught with the conventional method is significant at .05 alpha levels. The stated null hypothesis was therefore rejected.

\section{DISCUSSION}

This study has shown that students taught with differentiated instructional strategies had a higher mean achievement score (59.36) in Geometry than their counterparts taught with conventional method with (38.68) mean achievement score. This was further confirmed by the results in table 2 which reveals that the difference in achievement between the experimental and control groups was significant ( $\left.Z_{98}=11.320 ; P<.05\right)$. The reason for this higher achievement by the DIS group could be that the students were exposed with novel experiences which involved them in an active process of identifying links (steps) between concepts where new knowledge was reconciled, progressively differentiated and well integrated into previous knowledge already acquired by the students. It integrated ongoing and meaningful assessment with instruction, thus responding to individual students learning needs. This facilitated the experimental group better understanding of geometry concept over the control group students. These findings is in consonant with the guiding principle report of Tomlinson (2000) and Anderson (2007), indicating the efficacy of differentiated instruction in facilitating meaningful understanding of concepts and enhancing student's achievement. Sylwester (2003) reported that tiered learning tasks engage students slightly beyond what they find easy or comfortable in order to provide genuine challenge 
and meaningful learning. When concepts are meaningfully learnt and internalized, students' exhibits mastery and control over the subject matter leading to remarkable achievement in students' learning outcome.

The low achievement of the control group students as revealed by the results could be attributed on the defectiveness of the conventional lecture method in which students were only passive recipients of knowledge and were not actively involved in the learning process which deprived them from taking charge of their learning (Francisco, Nicoll \& Trautmann 1998). Table 3 shows that the retention mean scores (60.42) of students taught geometry with differentiated instructional strategies was higher than the retention mean scores (34.98) of those taught with the conventional lecture method. The reason for the higher knowledge retention ability for the experimental group is due to the fact that the use of differentiated instruction enhanced active students participation channeled into a cooperative learning environment through flexible grouping of students. This then enhanced in-dept and higher meaningful understanding of concepts, higher ability to internalize and retain learned concepts and higher ability to use knowledge. Table 4 reveals that the difference between the retention means scores of experimental and control groups is statistically significant $\left(Z_{98}=13.876 ; P<.05\right)$. This finding is in line with Levy (2008) and Anderson (2007). The above findings also agree with that of Nunley (2006) and Anderson (2007) that when an educator differentiate by product or performance , it affords the students various ways of demonstrating the mastery of the content, engage in harder and more cognitive complex task, and use of higher order thinking skills that necessitate retention of learned concepts.

\section{CONCLUSION}

The use of differentiated instructional strategies as a veritable and innovative instructional strategy in secondary school mathematics teaching and learning is one way of ensuring meaningful learning and internalization of mathematics concepts as against learning by rote which is the characteristic of conventional method.

Teaching geometry using differentiated instructional strategies is effective for retaining concepts in mathematics. Thus, differentiated instruction is very purposeful, efficient and an effective instructional strategy for increased meaningful understanding of abstract and difficult concepts as well as higher retention ability in mathematics concepts.

\section{RECOMMENDATION}

The following recommendations were made from the findings of the study:

- Mathematics teachers and educators should adopt the use of differentiated instructional strategies as a purposeful strategy to effectively teach geometry concept as well as other abstract and difficult mathematical concepts in order to make instruction meaningful and interesting.

- The Federal and State Governments and other educational bodies should organize technical workshops, seminars and regular in-service innovation-oriented training programs for teachers on the use of differentiated instructional strategies as an efficient and effective teaching strategy.

- The National Mathematical Centre should organize national workshop for teachers of mathematics on the use of this innovative strategy.

\section{REFERENCES}

Allan, S. D and Tomlinson, C. A., 2000. Leadership for differentiating schools and classrooms. Alexandria, VA: ASCD. Retrieved August 5, 2010 from http://www.ascd.org/publications/books/1 08051.aspx

Anderson, K. M., 2007. Tips for teaching: Differentiating instruction to include all students._Preventing School Failure, 51, (3): 49-54.

Francisco, J., Nicoll, G and Trautmann, M., 1998. Integrating multiple methods into a general chemistry classroom. Journal of chemical education 75, 210-213.

Kpolovie, P. J., 2010. Advanced Research Methods, Owerri: Springfield publishers Ltd. 
Levy, H. M., 2008. Meeting the needs of all students through differentiated instruction: Helping every child reach and exceed standards. The Clearing House, 81, (4): 161-164.

Nunley, K., 2006. Differentiating the High School Classroom: Solution Strategies for 18 Common Obstacles. Corwin Press: Thousand Oaks, CA.

Sylwester, R., 2003. A biological brain in a cultural classroom. Thousand Oaks, CA: Corwin press.

Theroux, P., 2004. Differentiating instruction. Alberta, CA: Enhance Learning with Technology Web site. Retrieved August 23, $2010 \quad$ from http://members.shaw.ca/priscillatheroux/ differentiating.html

Tomlinson, C. A., 2000. Differentiation of instruction in the elementary grades. ERIC Digest.

Retrieved Sept 2, 2010. from http://www.ericdigests.org/2001-

2/elementary.html

Tomlinson, C. A., 2001. Differentiated instruction in the regular classroom: What does it mean? How does it look? Understanding Our Gifted, 14, 3-6. 